\title{
LIDERANÇA RELACIONAL EM REDE DO SETOR DE TRANSPORTES BRASILEIRO
}

\section{Relational leadership in the network of the brazilian transport sector}

\section{Éderson Tomasi da Silva}

E-mail: ederson.tomasi@gmail.com

Mestre em Administração pela Universidade do Oeste de Santa Catarina; Especialista em MBA em

Inteligência Empresarial pela Fundação Getúlio Vargas; Gestor de Pessoas na Empresa Expresso São Miguel.

Endereço para contato: Acesso Plinio Arlindo de Nes, 2180 D, Belvedere, 89810-460, Chapecó, Santa Catarina, Brasil. https://orcid.org/0000-0002-8998-8443

Eliane Salete Filippim

E-mail: eliane.filippim@unoesc.edu.br

Pós-doutora em Administração Pública e Governo pela Fundação Getúlio Vargas; Doutora em Engenharia de Produção e Sistemas pela Universidade Federal de Santa Catarina; Membro da Sociedade Brasileira de Administração Pública. https://orcid.org/0000-0003-4064-1059

Anderson de Souza Sant'Anna

E-mail: anderson.santanna@fgr.br

Doutor em Administração, Comportamento Humano nas Organizações pela Universidade Federal de Minas Gerais; Professor na Fundação Getúlio Vargas de São Paulo; Professor na Fundação

Getúlio Vargas de São Paulo. https://orcid.org/0000-0001-6537-6314 
A gestão de uma empresa organizada em rede amplia a construção de relacionamentos que fortalecem a cooperação e a otimização de recursos para além do plano líder-liderado, requerendo articulação e cooperação entre os níveis individuais, organizacionais e societais, referenciando-se, portanto, no estilo de liderança relacional. Esta pesquisa teve como objetivo descrever os papéis e formas de liderança em uma empresa situada no Oeste catarinense que é identificada como uma organização com estrutura em rede. A pesquisa é classificada como um estudo de caso, realizado por meio de abordagem qualitativa, conduzida com a organização do segmento de transporte de cargas fracionadas, com unidades na região Sul do Brasil. Os dados foram coletados por meio de entrevista, observação, questionário e análise de documentos. Para análise dos dados, fez-se uso de análise de conteúdo e triangulação de diferentes fontes de evidências. Entre os principais resultados se aponta para a relevância de perfis de liderança diferenciados capazes de construção e sustentação de ambiências organizacionais mais flexíveis em que a integração e coordenação intra e interorganizacionais possam superar lógicas centradas no contratualismo formal, na burocracia e em práticas predominantes em configurações organizacionais funcionais que dificultam a transferência de conhecimentos, a criatividade e a inovação.

Palavras-chave: Liderança. Liderança relacional. Rede. Transportes.

\section{Abstract}

The management of a company organized in a network expands the construction of relationships that strengthen cooperation and the optimization of resources beyond the leader-led plan, requiring articulation and cooperation between individual, organizational and social levels. Referring, therefore, to the style of relational leadership, this article has the central purpose of presenting results of a study aimed at investigating the role and forms of performance of leadership in a Brazilian organization identified with organizational architecture oriented to the notion of network. The research can be classified as a case study, carried out through a qualitative approach, conducted with the organization of the fractionated cargo transportation segment, with units in the southern region of Brazil. Data were collected through interviews, observation, questionnaires and document analysis. For data analysis, content analysis and triangulation of different sources of evidence were used. Among the main results, it is pointed out the relevance of differentiated leadership profiles capable of building and sustaining more flexible organizational environments in which the intra and interorganizational integration and coordination can overcome logics centered on formal contractualism, bureaucracy and predominant practices in configurations functional organizational structures that hinder knowledge transfer, creativity and innovation.

Keywords: Leadership. Relational leadership. Network. Transport.

\section{INTRODUÇÃO}

Este estud o trata do tema da liderança no âmbito organizacional, e, mais especificamente, da liderança relacional em organizações com estrutura em rede. Compreendendo que a capacidade de liderança é indispensável para que organizações consigam atender às demandas internas, do mercado e da sociedade, o pressuposto básico foi cotejar a literatura disponível sobre o tema com achados de pesquisa empírica. O ponto de partida foi a trajetória de teorias que envolvem a liderança em diferentes dimensões e níveis. Nesse contexto, fez- 
se opção pela abordagem relacional, na medida em que visa compreender o fenômeno da liderança de forma mais ampla e sistêmica (Ospina, Kersh, \& Quick, 2014).

A organização alvo do estudo, atuante no segmento de transporte rodoviário de encomendas, foi fundada em 1995, no Oeste do Estado Santa Catarina, Brasil, e, atualmente, conta com 13 unidades próprias e 102 pontos de atendimento terceirizados, atendendo a 630 municípios distribuídos na região Sul do Brasil. Com aproximadamente 4 mil colaboradores diretos e indiretos e uma frota de cerca de 900 veículos, atende anualmente a mais de um milhão de clientes, contando com mais de 13 mil fornecedores. Em termos financeiros, a organização tem faturamento médio mensal acima de 26 milhões de reais e distribui receita paga em representações acima de 7 milhões de reais mensalmente.

Estruturada sob a lógica de rede, a organização compõe-se da matriz (empresa mãe), 13 unidades próprias e 102 administradas por terceiros, denominados prestadores de serviços. Um levantamento de dados preliminares permitiu constatar que cerca de $80 \%$ desses prestadores de serviços compreendem empreendedores com baixa experiência em gestão, evidenciando como principais dificuldades a liderança de pessoas e a separação entre propriedade e gestão. Já em nível das relações com a empresa mãe, verifica-se a deficiência de dispositivos de liderança capazes de melhor orientar os processos de coordenação e integração interorganizacionais. Diante desse quadro, a questão que orientou a pesquisa, cujos resultados serão apresentados neste artigo, pode ser assim delineada: qual o papel e formas de atuação da liderança em dinâmicas inter e intraorganizacional pautadas por arranjo organizacional em rede?

Para tal foi conduzida pesquisa de abordagem qualitativa, de natureza descritiva e interpretativa, considerando instrumentos múltiplos com vistas à coleta e análise de dados extraídos de documentos da organização, observação direta-do tipo não participante-, questionário e entrevistas semiestruturadas e em profundidade. Para a análise dos dados foi aplicada a técnica de triangulação de dados e de investigadores.

\section{REVISÃO DE LITERATURA}

Independentemente do setor e natureza do negócio, liderar e ou gerenciar apresentam-se como demandas intrínsecas e, não raro, desafiadoras. Notadamente no que se refere à liderança, a questão torna-se mais complexa, na medida em que um indivíduo não se vê reconhecido como detentor de competências em liderança por possuir traços ou características particulares, mas por mobilizar atributos, pessoais, organizacionais e ou societais na construção de relações de influência e mudança (Bergamini, 2009). 


\subsection{LIDERANÇA RELACIONAL}

A abordagem da liderança relacional entende que a dinâmica de influência abrange diferentes dimensões e níveis de análise-individual, organizacional e societal-, visando melhor compreender de que forma dinâmicas e interações complexas se coordenam e integram em diferentes esferas e escalas (Gittell, 2011; Sant'Anna, Nelson, \& Carvalho, 2015; Uhl-Bien, 2006).

De acordo com Uhl-Bien (2003), uma das precursoras dos estudos sobre o tema, a liderança relacional, pode ser entendida como a construção de um processo de influência social, que emana das vinculações entre o indivíduo, a organização e o contexto social no qual os agentes estão inseridos. Segundo ela, quatro pressupostos são requeridos à liderança relacional: a liderança decorre da utilização da influência para a geração da mudança; a liderança não se refere a uma posição formal (cargo ou título), mas a um comportamento; para a liderança gerar mudanças, necessita relações eficazes; a liderança torna-se cada vez mais eficaz à medida que - líder aprimora suas capacidades para construir e manter relações eficazes.

Day e Harrison (2007) afirmam que a liderança relacional implica interdependências entre indivíduos, equipe, organizações e sociedade. Para Sant'Anna et al. (2015), a liderança relacional estabelece uma relação de influência e mudança se o agente (líder) focalizar menos energia no desenvolvimento de mecanismos administrativos formais e laços de dependência em colegas e membros de sua equipe e mais no desenvolvimento de relações entre parceiros importantes.

Osborn, Uhl-Bien, e Milosevic (2014, p. 32) destacam que a liderança relacional emerge de processos sociais e da relação entre as pessoas, tendo como premissa que a liderança ocorre dentro do campo constituído pelos indivíduos e pela coletividade.

Ospina e Uhl-Bien (2012) relatam que por meio da liderança relacional é possível estudar a realidade invisível das relações existentes nos atores envolvidos no processo de liderança.

Por fim, a liderança relacional apresenta uma nova possibilidade de análise, sob um novo viés, o qual visa analisar as influências contextuais que refletem sobre a liderança, trazendo à tona o contexto e o processo ao se pesquisar liderança, já que o liderado passa a agir como corresponsável do processo, deixando de ser tratado meramente como um receptor passivo (Osborn et al., 2014).

Osborn et al. (2014, p. 33) apresentam que a liderança relacional acontece em casas/ localidades diferentes, porém sabendo da importância de suas atribuições para o todo e compreendendo a importância do trabalho de maneira única, o que vem ao encontro do objeto pesquisa deste estudo. 


\subsection{REDES}

Por sua vez, as arquiteturas e dinâmicas organizações em rede, de acordo com Leon (1998), fundamentam-se na busca por dispositivos estruturais capazes de propiciar redução nos níveis de incertezas e riscos intensificados nos contextos contemporâneos dos negócios e das relações inter e intraorganizacionais.

Para Ribault, Martinet, e Lebidois (1995), as organizações em rede complementamse nos planos de produção e comercialização. Para Olave e Amato (2001), a rede é um modo de associação por afinidade de natureza informal, que responsabiliza cada uma das organizações participantes por sua gestão e desenvolvimento, ampliando a escala dos processos de flexibilização organizacionais.

A rede na qual a empresa estudada atua como a centralizadora (empresa mãe) pode ser classificada, na proposta de Gandori e Soda (1995), como uma rede burocrática assimétrica, pois é regida por um contratado formal que visa regular a organização da rede e as condições de relacionamento entre os participantes.

Casarotto, Castro, Fiod, e Casarotto et al. (1998), ao tipificarem as redes de empresas, escrevem que a rede top-down é aquela na qual a pequena empresa pode se tornar fornecedora ou subfornecedora de uma empresa mãe. Nesse tipo de rede, o fornecedor é altamente dependente das estratégias da empresa mãe e tem pouca flexibilidade e poder de decisão. Entende-se que a rede na qual a empresa se encontra inserida é classificada como top-down, já que as empresas de menor porte fornecem seus serviços para a empresa mãe por meio da terceirização de serviços de coleta e entrega de mercadorias, que ocorre em determinada área de atuação preestabelecida contratualmente.

Para efeitos deste estudo, adotou-se o entendimento de Knorringa e Meyer-Stamer (1999), que caracterizam a rede estudada como uma rede formal, embasada na dimensão contratual existente entre as partes, nos mesmos moldes de uma franquia, porém seguindo os preceitos de representação usualmente utilizados pelo mercado de transportes.

\subsection{REDES E LIDERANÇA}

Casarotto et al. (1998) e Corrêa (1999) explicitam que o nascimento, a sobrevivência e a perenidade de redes estão diretamente relacionados ao equacionamento de três aspectoschave: cultura de confiança, cultura de competência e cultura de tecnologia da informação.

Quanto à cultura de confiança, Corrêa (1999) refere-se ao fortalecimento da confiança entre os parceiros, sendo que, no caso da empresa estudada, diz respeito ao papel dos líderes, que devem agir de maneira cooperativa, respeitando a cultura e os interesses das 
pessoas e das empresas. A ausência da cultura de confiança nos líderes responsáveis pela condução e manutenção da rede é sinônimo de falência da gestão organizacional e da rede.

Já quanto ao aspecto cultura de competência, o foco está relacionado à identificação e exploração das competências essenciais de cada um dos parceiros, englobando aspectos tangíveis e intangíveis. Olave e Amato (2001) propõem que os parceiros sejam avaliados com base no valor agregado com o cliente final, na força de diferenciação que ele gera para a rede, bem como na força de resistência que ele possui para barrar ações de concorrentes e pela sua flexibilidade/adaptabilidade a variações e sazonalidades às quais a rede está exposta.

Em uma era altamente tecnológica, a cultura da tecnologia da informação está intrinsecamente relacionada com a capacidade da rede e de seus agentes em dar agilidade ao fluxo de informações e de utilizar e otimizar recursos computacionais para processamento de dados.

Assim, constata-se ampla sinergia entre as noções de liderança relacional e configurações rediais, notadamente, no contexto atual, em que os processos de desfronteirização organizacional e terceirização, não apenas de processos produtivos, mas igualmente da gestão, fazem-se evidenciar. Como decorrência dos novos formatos de divisão do trabalho, cabe às empresas mãe as funções estratégicas, de integração, coordenação e liderança; assim como às "empresas-filhas" a produção e gestão (Casarotto et al., 1998).

Nesse contexto, o desafio consiste em como identificar e desenvolver competências em liderança que propiciem a sinergia entre os diferentes estratos da rede, minimizando tensões e conflitos decorrentes de assimetrias entre os distintos "nós" da rede. Para Nunes (2010), caberá ao líder relacional, haja vista sua posição, em arranjos organizacionais, multidimensões, relacionais e multiníveis, de agente fundamental à construção de vínculos; mobilização de competências individuais e de equipes multifuncionais, multivínculos e multiculturais; e catalisação de mudanças que pressupõem novas formas de mediação e antecipação.

Ademais, a noção de liderança relacional apresenta-se oportuna como marco teórico do estudo ao reconhecer e ter por base a complexa interação existente entre distintos agentes sociais, organizacionais e individuais (Nunes, 2010). Já como marco teórico de rede, a opção foi pela abordagem de Fleury e Fleury (2003), os quais a compreendem como estruturadas e sustentadas por competências organizacionais e individuais que, por sua vez, influenciam diretamente as estratégias competitivas da organização, gerando, ou não, vantagem competitiva, bem como distintos impactos societais. Foi considerada também a perspectiva teórica de Knorringa e Meyer-Stamer (1999), que possibilitou caracterizar a rede objeto desta investigação como formal, embasada na dimensão contratual existente entre as partes, nos mesmos moldes de uma franquia, porém seguindo os preceitos de agenciamento usualmente utilizados pelo mercado de transportes. 


\section{PROCEDIMENTOS METODOLÓGICOS}

Quanto à sua caracterização, a pesquisa pode ser classificada como descritiva de abordagem qualitativa (Godoi, Mello, \& Silva 2010), e do ponto de vista metodológico utilizou-se o estudo de caso como método de pesquisa. Cabe salientar que a decisão pelo estudo de caso único foi fundamentada nas observações de Yin (2010), que argumenta que esse tipo de estudo pode representar um projeto típico e que, a partir dele, podem ser tiradas lições que podem iluminar outros casos. $O$ caso único eleito foi, portanto, focado na relação entre empresa mãe e suas unidades de negócio, especialmente prestadores de serviços (empresas filhas). Buscou-se captar e descrever a percepção dos sujeitos investigados, que, nesse caso, foram empreendedores das unidades de negócio da organização.

Para tal, recorreu-se a múltiplas fontes de evidência (Godoi et al., 2010). Inicialmente, procedeu-se à pesquisa exploratória, utilizando os três grupos principais de evidências: análise de documentos, observação direta-do tipo não participante-, e entrevistas semiestruturadas e em profundidade.

Sobre a análise de documentos, foram identificados, classificados e analisados documentos pertinentes à interação empresa mãe/empresas filhas. Especialmente, foram detalhadamente analisados os contratos e termos aditivos firmados entre os prestadores de serviços e a organização, visando identificar particularidades e clarificar a classificação das unidades ("nós" da rede), tendo por base os papéis, responsabilidades e porte.

Já a etapa de observação direta compreendeu a participação em reuniões e atividades desenvolvidas entre a empresa mãe e as empresas filhas. Adotando o critério de saturação, foram realizadas inserções em oito reuniões, envolvendo seis diferentes empresas filhas.

Como principal instrumento de dados foi aplicado questionário a 102 empreendedores de empresas filhas ligadas à empresa mãe. Igualmente composto por questões mensuradas em escala de Likert (1975), um segundo questionário foi aplicado a 41 representantes da empresa mãe, sendo 3 conselheiros, 3 diretores, 13 gestores corporativos e 12 gestores de unidades de negócios administrados pela própria instituição. Ambos os questionários foram estruturados com base na metodologia Personal Development Analysis (PDA), desenvolvida em 1928, a partir dos estudos realizados por Marston.

Finalmente, entrevistas foram conduzidas com o conselheiro responsável pela estruturação da rede, 3 diretores e 3 gestores de unidades de negócios da empresa mãe, assim como a 11 empreendedores das empresas filhas. Cabe destacar como critérios para composição dos entrevistados: não entrevistar empreendedores de empresas filhas com grau de parentesco com o conselho e com a direção da empresa mãe; empresas ilhas com faturamento significativo no contexto geral da organização (soma do frete emitido mais o frete recebido); observar perfil da unidade (expedidora, equilibrada ou recebedora); observar 
porte da unidade, baseado no valor recebido pelo agenciador pelos serviços prestados; observar sexo do(a) empreendedor(a), visando mesclar pessoas com tempo de empresa, idade e sexo diferenciados, por faixa de porte em que está classificada a unidade.

Por meio das entrevistas, buscou-se também aprofundar achados quanto ao estilo e dispositivos de legitimação das ações de influência adotados pelos entrevistados, nas instâncias intra e interorganizacionais. Para assegurar a compreensão do fenômeno estudado, foi aplicada a técnica de triangulação, por meio da combinação de diferentes maneiras de analisar as evidências capturadas (Densin \& Lincoln, 2005). Além da triangulação, foi utilizada a técnica de análise de conteúdo $(A C)$, que consiste na análise da comunicação, dando ênfase ao conteúdo das mensagens ditadas pelos sujeitos de pesquisa (Triviños, 1987). Os dados coletados foram analisados a partir de categorias de análise (Tabela 1), elaboradas com base na revisão da literatura.

Tabela 1

Categorias de análise e descritores

\begin{tabular}{ll}
\hline \multicolumn{1}{c}{ Categorias } & \multicolumn{1}{c}{ Descritores } \\
\hline & - Dados contextuais de identificação; \\
& - Caracterização da empresa; \\
Características da empresa & - Prestadores de serviço (empresas filhas); \\
e da sua atuação em rede & - Porte das agências; \\
& - Compreensão e visão da rede; \\
& - Redes: entendimento da estruturação da empresa. \\
\hline \multirow{2}{*}{ Liderança } & - Liderança relacional; \\
\hline
\end{tabular}

Por fim, na Figura l, pode-se vislumbrar uma síntese do desenho e procedimentos metodológicos adotados.

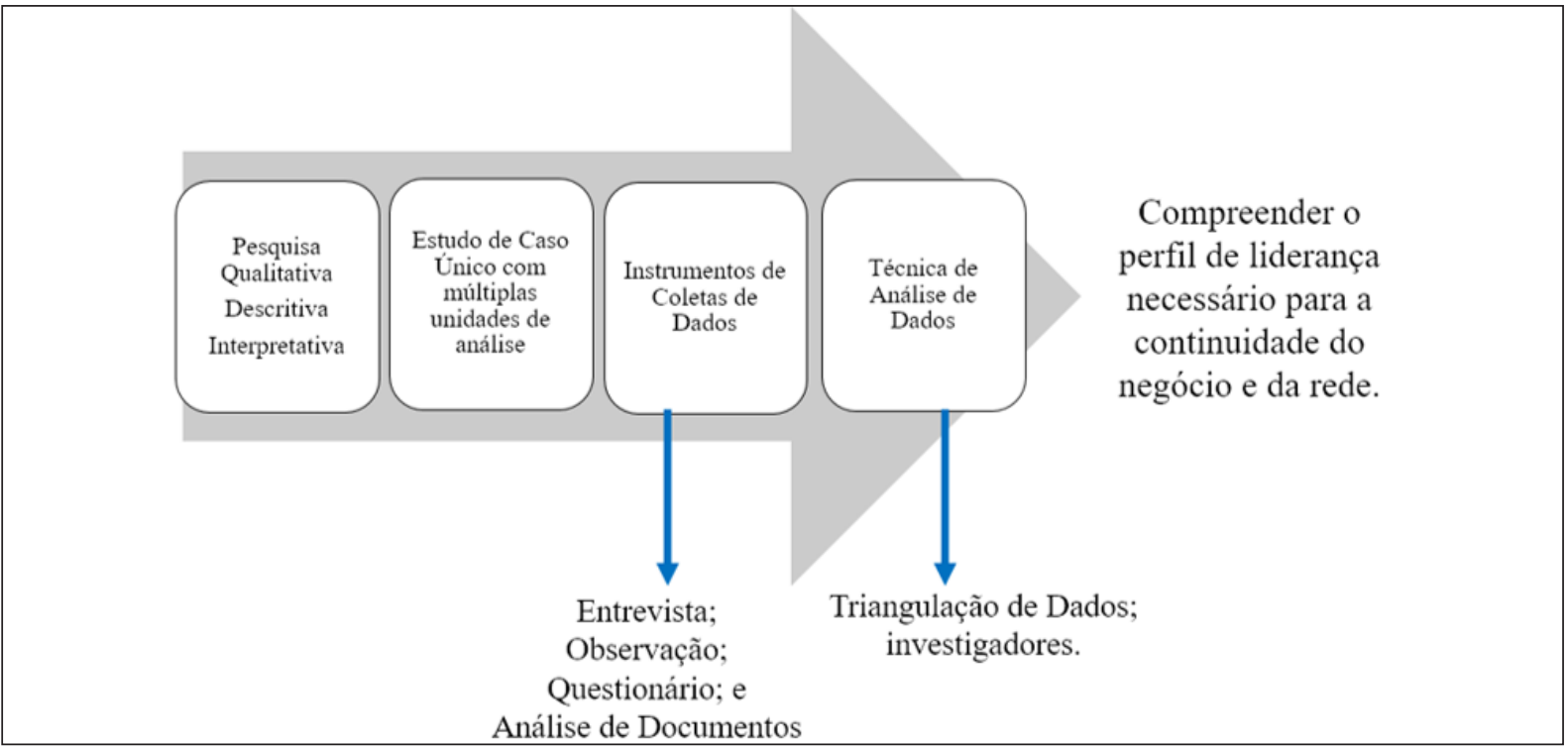

Figura 1. Síntese dos procedimentos metodológicos. 


\section{APRESENTAÇÃO E ANÁLISE DOS DADOS}

Nesta seção é apresentado o conjunto dos dados coletados, analisados considerando características da empresa, sua atuação em rede e dispositivos de liderança relacional identificados.

\subsection{CARACTERÍSTICAS DA EMPRESA E DA SUA ATUAÇÃO EM REDE}

A organização alvo deste estudo foi fundada em 1995 por dois sócios, os quais iniciaram suas operações com quatro rotas de transferências, uma sede própria e quatro sedes terceirizadas. Em 2013, a empresa profissionaliza sua gestão, incorporando um conselho de administração composto por representantes das famílias proprietárias. Em 2016, a organização implanta arranjo organizacional, tendo por base a arquitetura de rede, retirando de sua estrutura própria as atividades de gestão e prestação de serviços. Como decorrência, constata-se, por meio de diversos depoimentos, implicações de tal alteração na cultura da organização, em particular nos processos de tomada de decisão. De toda forma, registra-se, ainda hoje, significativa influência dos fundadores, com descentralização das atividades operacionais e decisões táticas, porém com forte concentração, na empresa mãe, daquelas de nível estratégico.

Nessa direção, a partir dos dados foi possível constatar também foco atribuído pela empresa mãe no desenvolvimento de processos internos de liderança orientada à regulação, com ênfase em competências de governança corporativa, nos moldes preconizados pelo Instituto Brasileiro de Governança Corporativa (IBGC, 2014), visando integrar, mesmo sendo uma empresa de capital fechado, lógica de organização atuante no mercado aberto.

Quanto aos gestores das empresas filhas, grande ênfase é dada pela empresa mãe à construção de uma imagem interna e externa que associa tais gestores a "empreendedores de mercado". Como artefato de construção de tal imaginário, não são aceitos como dirigentes das empresas filhas investidores da empresa mãe. Nas palavras de um dos gestores da empresa mãe, M. Martins, os empreendedores das empresas filhas devem

\footnotetext{
... ser o dono do seu negócio. Ele é que tem que dar a diretriz para onde que ele quer que a empresa dele vá, porque o nosso contrato com ele é um contrato de empresa com empresa, ele não é um colaborador nosso (Informação verbal, 24 de novembro de 2016).
} 
Nessa direção, não se constataram relatos quanto a ingerências da empresa mãe na gestão das empresas filhas. Porém, constata-se que os processos de qualificação e preparação do trabalho de seus membros são controlados pela empresa mãe, conforme F. Santos, "[. . .] visando garantir que as políticas e diretrizes organizacionais se estendam por toda a rede" (Informação verbal, 24 de novembro de 2016).

Além disso, relatos de empreendedores das empresas filhas apontam para a tônica da empresa mãe quanto à difusão e implementação dos procedimentos e normas de atendimento por ela estabelecidos. Segundo um dos empreendedores, M. Martins, "Eu sou o dono do negócio, mas como são duas empresas, nós temos um contrato com eles, então eu tenho que cumprir algumas regras deste contrato, que seriam coletas de produtos e entregas" (Informação verbal, 24 de novembro de 2016).

Coerentemente ao apontado por Casarotto et al. (1998) e Corrêa (1999), os achados deste estudo apontam para um modelo de rede ainda fortemente centrado em lógica burocrática, formal e top-down, baseada no desenvolvimento e aprimoramento do "aspecto de uma cultura de competência", excluindo, todavia, aspectos associados a relações efetivamente mais centradas nas noções de cooperação e parceria.

Mesmo evidenciada a necessidade de cada unidade ter sua gestão e exercer liderança mais profissional com a empresa mãe, não foi possível identificar, por parte desta, ações direcionadas ao desenvolvendo de processos de liderança capazes de interações intra e interorganizacionalmente mais sistêmicas, ou de valorização da transferência de conhecimentos e experiências entre os membros da rede. $O$ conjunto dos depoimentos coletados, tanto dos entrevistados da empresa mãe quanto da rede, reforçam uma espécie de "cultura da competência", porém, centrada apenas nos níveis operacionais do negócio e nas atribuições que necessitam ser geridas para o efetivo alcance dos termos e resultados contratualmente estabelecidos.

Isso, em um contexto em que mais de $90 \%$ dos membros da rede apontam não possuir experiência em gestão, em particular, na gestão de seus elementos humanos e/ou de atuar como líderes. Ou, ainda, revelam ser oriundos da própria empresa mãe: muitos deles antigos motoristas que trabalhavam com frete tipo carreto ou mudanças. Confessam, assim, na transição de empregados para "empreendedores", a não superação de lacunas no desenvolvimento de competências relacionadas, além da gestão de pessoas, à gestão administrativo-financeira do empreendimento, agora sob sua responsabilidade. A Tabela 2 permite visualizar um panorama do perfil dos empreendedores das empresas filhas participantes da rede: 
Tabela 2

Características dos empreendedores das empresas filhas pertencentes à rede

\begin{tabular}{|c|c|c|c|c|c|c|c|c|}
\hline \multicolumn{3}{|c|}{ Respostas por Gênero } & \multicolumn{3}{|c|}{ Respostas por Formação Superior } & \multicolumn{3}{|c|}{ Atividade Anterior } \\
\hline Masculino & 59 & $74,68 \%$ & Administração & 21 & $26,58 \%$ & Gerente & 11 & $13,92 \%$ \\
\hline Feminino & 20 & $25,32 \%$ & Ciências Contábeis & 7 & $8,86 \%$ & Ex-funcionário & 9 & $11,39 \%$ \\
\hline \multirow[t]{2}{*}{ Total } & 79 & & Engenharia & 4 & $5,06 \%$ & Vendedor & 7 & $8,86 \%$ \\
\hline & & & Direito & 2 & $2,53 \%$ & Transportador & 6 & $7,59 \%$ \\
\hline \multicolumn{3}{|c|}{ Respostas por Estado Civil } & Farmácia & 2 & $2,53 \%$ & Auxiliar Administrativo & 5 & $6,33 \%$ \\
\hline & & & $\begin{array}{l}\text { Tecnólogo em Estética e } \\
\text { Cosmética }\end{array}$ & 1 & $1,27 \%$ & $\begin{array}{l}\text { Representante Comer- } \\
\text { cial }\end{array}$ & 5 & $6,33 \%$ \\
\hline Casado(a) & 49 & $62,03 \%$ & Educação Física & 1 & $1,27 \%$ & Empresário & 4 & $5,06 \%$ \\
\hline União Estável & 15 & $18,99 \%$ & Gestão Imobiliária & 1 & $1,27 \%$ & Contador & 3 & $3,80 \%$ \\
\hline Solteiro(a) & 10 & $12,66 \%$ & Informática & 1 & $1,27 \%$ & Estudante & 3 & $3,80 \%$ \\
\hline Convivente & 2 & $2,53 \%$ & Logística & 1 & $1,27 \%$ & Motorista & 3 & $3,80 \%$ \\
\hline Separado(a) & 2 & $2,53 \%$ & Matemática & 1 & $1,27 \%$ & Bancário & 2 & $2,53 \%$ \\
\hline Divorciado & 1 & $1,27 \%$ & Serviço Social & 1 & $1,27 \%$ & Comerciário & 2 & $2,53 \%$ \\
\hline \multirow[t]{2}{*}{ Total } & 79 & & Total & 43 & & Financeiro & 2 & $2,53 \%$ \\
\hline & & & & & & Emissor de Passagens & 2 & $2,53 \%$ \\
\hline \multicolumn{3}{|c|}{ Respostas por Faixa Etária } & Tempo na Rede & & & Funcionário Público & 2 & $2,53 \%$ \\
\hline & & & & & & Prestador de Serviços & 2 & $2,53 \%$ \\
\hline 46 a 50 anos & 18 & $22,78 \%$ & De 10 a 14 anos & 24 & $30,38 \%$ & Primeiro Emprego & 2 & $2,53 \%$ \\
\hline 41 a 45 anos & 16 & $20,25 \%$ & De 5 a 9 anos & 18 & $22,78 \%$ & Atendente & 1 & $1,27 \%$ \\
\hline 36 a 40 anos & 15 & $18,99 \%$ & De 15 a 19 anos & 14 & $17,72 \%$ & Caminhoneiro & 1 & $1,27 \%$ \\
\hline 31 a 35 anos & 10 & $12,66 \%$ & De 1 a 2 anos & 7 & $8,86 \%$ & Consultor & 1 & $1,27 \%$ \\
\hline 26 a 30 anos & 9 & $11,39 \%$ & De 3 a 4 anos & 7 & $8,86 \%$ & Costureira & 1 & $1,27 \%$ \\
\hline 51 a 55 anos & 7 & $8,86 \%$ & Mais de 20 anos & 6 & $7,59 \%$ & Despachante & 1 & $1,27 \%$ \\
\hline Mais de 55 anos & 3 & $3,80 \%$ & Menos de 1 ano & 3 & $3,80 \%$ & Estagiária & 1 & $1,27 \%$ \\
\hline 21 a 25 anos & 1 & $1,27 \%$ & Total & 79 & & Professor & 1 & $1,27 \%$ \\
\hline \multirow[t]{2}{*}{ Total } & 79 & & & & & Trabalhador Autônomo & 1 & $1,27 \%$ \\
\hline & & & Tempo no segmento de tr & anspo & & Técnico em Telefonia & 1 & $1,27 \%$ \\
\hline \multicolumn{3}{|c|}{ Respostas por Escolaridade } & & & & Total & 79 & \\
\hline & & & Mais de 20 (vinte) anos & 30 & $37,97 \%$ & & & \\
\hline $\begin{array}{l}\text { Ensino Médio } \\
\text { Completo }\end{array}$ & 21 & $26,58 \%$ & $\begin{array}{l}\text { De 10(dez) a 14(quator- } \\
\text { ze) anos }\end{array}$ & 18 & $22,78 \%$ & & & \\
\hline Superior Completo & 19 & $24,05 \%$ & $\begin{array}{l}\text { De } 15 \text { (quinze) a } 19 \text { (deze- } \\
\text { nove) anos }\end{array}$ & 15 & $18,99 \%$ & & & \\
\hline $\begin{array}{l}\text { Superior Incom- } \\
\text { pleto }\end{array}$ & 16 & $20,25 \%$ & $\begin{array}{l}\text { De } 5 \text { (cinco) a } 9 \text { (nove) } \\
\text { anos }\end{array}$ & 9 & $11,39 \%$ & & & \\
\hline $\begin{array}{l}\text { Ensino Fundamen- } \\
\text { tal Completo }\end{array}$ & 7 & $8,86 \%$ & $\begin{array}{l}\text { De 3(três) a 4(quatro) } \\
\text { anos }\end{array}$ & 5 & $6,33 \%$ & & & \\
\hline $\begin{array}{l}\text { Ensino Médio } \\
\text { Incompleto }\end{array}$ & 6 & $7,59 \%$ & De 1(um) a 2(dois) anos & 2 & $2,53 \%$ & & & \\
\hline $\begin{array}{l}\text { Pós Graduação } \\
\text { Completa }\end{array}$ & 5 & $6,33 \%$ & Menos de 1 (um) ano & 0 & $0,00 \%$ & & & \\
\hline $\begin{array}{l}\text { Pós Graduação } \\
\text { Incompleta }\end{array}$ & 3 & $3,80 \%$ & Total & 79 & & & & \\
\hline $\begin{array}{l}\text { Ensino Fundamen- } \\
\text { tal Incompleto }\end{array}$ & 2 & $2,53 \%$ & & & & & & \\
\hline Total & 79 & & & & & & & \\
\hline
\end{tabular}

Nota. De 102 pesquisados, 79 responderam (77,45\%).

Vale acrescentar que o principal critério utilizado pela empresa mãe na seleção dos empreendedores filhos é a capacidade de investimento (capital financeiro) para suportar a 
estruturação da unidade de negócio, a partir da crença que o empreendedor/prestador de serviços aprenderá administrar seu negócio com treinamentos e orientações prescritas nos processos e regulamentos repassados pela organização.

Isso, todavia, sinaliza para um viés de visão da empresa mãe, em particular no que se refere à adoção da noção de "rede". Evidência disso são relatos quanto à demanda crescente de sua intervenção na mediação de conflitos dentro das empresas, entre elas e delas consigo, ocasionando, não raro, rupturas de contrato, como observado por alguns dos entrevistados, como O. Smaniotto e N. Caregnatto, respectivamente: "Hoje não é só o dinheiro que deve contar para ser escolhido para ser parceiro da empresa; têm vários outros critérios: passar por uma seleção, demonstrar claro o seu capital, seu veículo" (Informação verbal, 24 de novembro de 2016). Ou ainda, de forma mais explicita: "[. . .] se há conflito-claro que háesses conflitos sempre são administrados pela empresa mãe" (Informação verbal, 25 de novembro de 2016).

Segundo relato de entrevistado responsável pela atração de novas empresas filhas, C. Bona, a empresa mãe tem se deparado com a necessidade de rever a permanência de empreendedores mais antigos na rede: "Aparentemente eles se cansam por ter que administrar pessoas elou não conseguir separar suas despesas particulares daquelas da unidade de negócio" (Informação verbal, 25 de novembro de 2016). Tais achados evidenciam, ainda mais fortemente, a relevância de iniciativas de flexibilização organizacional, com inspiração ou bricolagens a partir de conceitos, como o de "redes", aprofundarem-se na análise de implicações derivadas de estratégias centradas na redução de custos, via terceirização dos processos transacionais e de gestão, sem revisão mais sistemática de pressupostos típicos de estruturas funcionais, centradas no formalismo contratual, na burocracia e em formas tradicionais de controle.

Certamente tais dificuldades têm como base as contradições e os paradoxos advindos da dicotomia entre a "lógica de flexibilidade", inerente ao conceito de "redes", e a "lógica da competência", utilizando expressão adotada pela empresa mãe, fortemente embasada na dominação legal, conforme apontado em diversos depoimentos de empreendedores da rede, como o de M. Martins: "Está no contrato! Isso é a primeira coisa que a empresa mãe questiona e deixa muito claro" (Informação verbal, 24 de novembro de 2016).

Em termos financeiros, por se tratar de contrato de pessoa jurídica com pessoa jurídica, o pagamento é realizado com base no volume e na quantidade de serviços prestados pelas empresas filhas. Apurou-se que cada unidade de negócio atua dentro da área de abrangência previamente contratada, não sendo cobrado nenhum valor das empresas filhas a título de franquias elou qualquer outro.

Por ser o pagamento aos empreendedores da rede realizado com base no volume e na quantidade de serviço realizado (faturamento da unidade), com pesos diferenciados de 
remuneração por distância do frete vendido e por expedição e recepção das mercadorias, realizou-se, para esta pesquisa, uma análise e subdivisão das empresas filhas, conforme consta na Tabela 3:

Tabela 3

Porte das unidades terceiras

\begin{tabular}{|c|c|c|}
\hline Porte & Faturamento & Comissão \\
\hline Expedidoras & $\begin{array}{l}\text { Unidades com a maior fatia de faturamento baseado em } \\
\text { sua produção (mais de } 60 \% \text { do faturamento) }\end{array}$ & $\begin{array}{l}\text { Possuem comissionamento igual } \\
\text { ou superior a sessenta mil reais. }\end{array}$ \\
\hline Equilibradas & $\begin{array}{l}\text { Unidades com faturamento balanceado entre o que produz } \\
\text { (expede) e o que recebe (Entre } 41 \% \text { e } 59 \% \text { ) }\end{array}$ & $\begin{array}{l}\text { Independe o valor de comis- } \\
\text { sionamento pelo equilíbrio na } \\
\text { produção da receita. }\end{array}$ \\
\hline Recebedoras & $\begin{array}{l}\text { Unidades que possuem a sua fonte de receita centrada na } \\
\text { recepção. Mais de } 60 \% \text { do faturamento da unidade está } \\
\text { baseado na recepção de mercadorias. }\end{array}$ & $\begin{array}{l}\text { Normalmente sua fonte de recei- } \\
\text { ta mensal é inferior a sessenta } \\
\text { mil reais. }\end{array}$ \\
\hline
\end{tabular}

\subsection{LIDERANÇA}

Ao serem abordados sobre o tema liderança, os respondentes citam, prioritariamente, o que tem relação com atributos pessoais, porém já assinalam um caráter mais relacional do processo. Segundo o Entrevistado 1, "[. . .] o líder é aquele que consegue transitar bem entre as pessoas com que possui relação, com os colaboradores dele, com os seus subordinados, seus pares e seus superiores e juntamente com todos os órgãos que ele toca todos os dias" (Informação verbal, 24 de novembro de 2016).

Outros sinalizam a liderança como natural do sujeito, conforme o Entrevistado 2:

A liderança é conquistada. Ela não é imposta. A forma como as pessoas agem, do jeito que elas tratam as situações adversas, acho que já caracteriza o líder. Acho que você percebe que uma pessoa tem traços de liderança ao ver como ela trata seus pares, seus subordinados e seus superiores (Informação verbal, 25 de novembro de 2016).

Por outro lado, gestores de áreas mais operacionais da empresa mãe, com maior contato com a rede, possuem visões distintas de liderança, adotando em suas falas concepções mais relacionadas à liderança transformacional e até mesmo à transacional. Esse aspecto pode ser observado em relatos que enfatizam, uma vez mais, atributos individuais, associados ao poder pessoal e ao carisma, como o relato do Entrevistado 3: "A liderança nasce, muitas vezes, com a pessoa. Você tem que aperfeiçoar ela, a equipe tem que enxergar o cara como líder e tem que se abraçar com ele" (Informação verbal, 25 de novembro de 2016).

Em outra passagem, do Entrevistado 3, registra-se que "o líder tem que conduzir a equipe dele, ele não pode ter rotatividade, ele tem que repassar como tem que ser conduzida 
a unidade de negócio dele, dentro das normas da empresa mãe" (Informação verbal, 25 de novembro de 2016). Nesse mesmo sentido, o Entrevistado 4 citou que:

O líder tem que ser um cumpridor de regras, ele tem que ser um cumpridor de prazos. Ele tem que fazer o papel do dia a dia, ele tem que estar ativo no processo, ser participativo com os demais funcionários dele no dia a dia (Informação verbal, 24 de novembro de 2016).

Mesmo os gestores da empresa mãe com relacionamentos mais próximos às empresas filhas se confessam mais focados em fazer com que tarefas sejam executadas, reconhecendo os empreendedores das empresas filhas, não raro como meros intermediadores, senão executores dos contratos firmados. Os dados da Tabela 4 agrupam as principais definições atribuídas pelos respondentes à noção de liderança:

Tabela 4

Visão dos sujeitos de pesquisa sobre "Ser líder e liderar é..."

1A) Liderar é: $\quad$ Qtd. $\quad \begin{aligned} & \% \text { do } \\ & \text { Total }\end{aligned}$ Estilo de Liderança

\begin{tabular}{|c|c|c|c|}
\hline $\begin{array}{l}\text { Liderar é desenvolver senso de compromisso, respeito mútuo e } \\
\text { relações de confiança }\end{array}$ & 57 & $72,15 \%$ & Relacional \\
\hline Liderar é construir ambientes participativos e colaborativos. & 22 & $27,85 \%$ & Transformacional \\
\hline Liderar é compartilhar valores, normas e crenças. & 0 & $0,00 \%$ & Transacional \\
\hline IB) Ser líder é: & Qtd. & $\begin{array}{l}\% \text { do } \\
\text { Total }\end{array}$ & Estilo de Liderança \\
\hline Ser líder é acompanhar, monitorar e distribuir tarefas. & 38 & $48,10 \%$ & Transformacional \\
\hline $\begin{array}{l}\text { Ser líder é desenvolver consciência individual e social entre os } \\
\text { membros da equipe. }\end{array}$ & 28 & $35,44 \%$ & Relacional \\
\hline $\begin{array}{l}\text { Ser líder é desenvolver mecanismos administrativos formais e } \\
\text { laços de dependência com os membros da equipe. }\end{array}$ & 13 & $16,46 \%$ & Transacional \\
\hline 1C) Liderar é: & Qtd. & $\begin{array}{l}\% \text { do } \\
\text { Total }\end{array}$ & Estilo de Liderança \\
\hline $\begin{array}{l}\text { Liderar é um processo social que ocorre por meio da construção } \\
\text { de relacionamentos entre os indivíduos. }\end{array}$ & 52 & $65,82 \%$ & Relacional \\
\hline Liderar é gestar por meio de regulamentos, leis e regras. & 27 & $34,18 \%$ & Transacional \\
\hline Liderar é gestar por crenças e tradições. & 0 & $0,00 \%$ & Transformacional \\
\hline ID) Ser líder é: & Qtd. & $\begin{array}{l}\% \text { do } \\
\text { Total }\end{array}$ & Estilo de Liderança \\
\hline $\begin{array}{l}\text { Ser líder é construir compromisso entre os membros de uma equi- } \\
\text { pe por meio de sistemas sociais. }\end{array}$ & 43 & $54,43 \%$ & Relacional \\
\hline $\begin{array}{l}\text { Ser líder é ser seguido pelo que representa para a equipe, seus } \\
\text { valores e comportamentos. }\end{array}$ & 34 & $43,04 \%$ & Transformacional \\
\hline Ser líder é ser seguido pela posição que ocupa. & 2 & $2,53 \%$ & Transacional \\
\hline
\end{tabular}




\begin{tabular}{lrrr}
\hline \multicolumn{1}{c}{ IE) Liderar é: } & Otd. & $\begin{array}{l}\% \text { do } \\
\text { Total }\end{array}$ & Estilo de Liderança \\
\hline $\begin{array}{l}\text { Liderar é ter compromisso com as obrigações em comum, zelando } \\
\text { pelo respeito e pela confiança recíproca. }\end{array}$ & 49 & $62,03 \%$ & Relacional \\
Liderar é ser um agente de mudança e ter relações eficazes. & 20 & $25,32 \%$ & Transformacional \\
Liderar é ter boa dicção, poder de persuasão e negociação. & 10 & $12,66 \%$ & Transacional \\
\hline
\end{tabular}

Dos cinco quesitos reunidos na Tabela 4 chama a atenção que a única alternativa na qual a liderança relacional não figurou no topo se relaciona com a realização de tarefas, o que traz novamente à tona a ênfase, conforme o Entrevistado 4, "ao fazer, ao cumprir obrigações" (Informação verbal, 24 de novembro de 2016).

Um dos desafios deste estudo é analisar a legitimação da liderança em uma empresa que se constitui organizada em rede. Pela análise da documentação existente, pelas formas com que se observou serem conduzidas as reuniões, procedidas cobranças e repassadas informações, o estilo de liderança predominante nas relações entre empresa mãe e empresas filhas se centra na lógica da dominação legal, conforme entendimento de Knorringa e Meyer-Stamer (1999), pois se encontra embasada na dimensão contratual existente entre as partes, nos mesmos moldes de uma franquia, porém seguindo preceitos de representação, via formas centralizadas e autocráticas, como citou o Entrevistado 5:

\footnotetext{
... hoje, respeitando o contrato, o empreendedor recebe um veículo carregado, o que ele tem que fazer é cumprir os prazos de entrega que são definidos no contrato . . . . ele tem autonomia para gestar a equipe dele ...., tem essa autonomia de trabalhar com a equipe da forma como ele bem entender, ele tem que cumprir o que está escrito no contrato (Informação verbal, 25 de novembro de 2016).
}

Visando corroborar o estilo vigente, ao se analisar as trocas de informações, assim como a transferência de conhecimentos entre as empresas da rede, é unânime a constatação da comunicação como variável crítica, destacando-se a prevalência de ações pontuais e esporádicas, conforme destacou o Entrevistado 6:

Eu acho que o crescimento, a evolução da empresa mãe é o meu crescimento, é a minha evolução também como parceiro dela. As empresas filhas, no entanto, são muito mal informadas. A gente virou uma prefeitura: encheu-se de setores inoperantes ... Acho que ficaram muitas lacunas e arestas. Sabe, ela tentou se estruturar, ela criou setores, criou isso e aquilo, encheu de gente, mas não funciona .... porque ninguém tem o poder de decisão (Informação verbal, 7 de janeiro de 2017). 
Depoimentos apontam, também, que muitos dos empreendedores esperam que os gestores da empresa mãe mandem. Tal visão remete ao conceito da liderança transacional, que, segundo Bass (1985), prevê a aceitação por parte do líder e do subordinado de seus papéis, em que o subordinado fica aguardando ordens do líder. Para Bergamini (2009), trata-se muito mais de uma maneira de exercer o controle por meio do poder do que de liderar.

No mais, como a relação se processa sem se buscar compreender diferenças existentes dentro e entre as empresas da rede, tratando-se todos, independentemente de conhecimentos, experiências e porte da unidade da qual são responsáveis, de maneira igualitária, traços do estilo de liderança transacional parecem se sobrepor aos do estilo transformacional.

De acordo com Casagrande e Lavarda (2015), com base nos estudos realizados por Johnson, Dowd, e Ridgeway (2006), a legitimação ocorre pela presunção e compartilhamento de valores, normas e crenças, ao mesmo tempo que constroem uma dada realidade social coletiva que valida essa ordem social e faz com que os indivíduos ajam respeitando-as, mesmo estando em desacordo com elas. Evidente é a questão da presunção e compartilhamento de normas, pela quantidade de documentos-contratos, manuais, comunicados, ofíciosexistentes dentro da empresa mãe, porém também se destaca, pelos dados colhidos, que os valores e as crenças existentes estão muito mais alinhados com a primeira geração da administração do que com a atual gestão da rede.

Ao serem questionados sobre quem são suas principais referências e em quem se espelham para desempenhar suas atribuições, os entrevistados com mais de três anos na rede citaram o conselheiro que os contratou e o antigo gerente responsável pela implantação da rede, tecendo referências à postura, ao retorno, à cobrança e à orientação que deles foram recebidas.

Sendo a rede constituída por $89,2 \%$ de empreendedores de empresas filhas contratados pelos sociofundadores, é plausível presumir que a primeira gestão ainda impacta a forma de agir da rede e, particularmente, tem efeitos na gestão. É possível que novos preceitos, orientações e maneiras de trabalhar que estão sendo implantados ainda precisem ser mais difundidos e trabalhados no interior da empresa mãe e na rede.

Infere-se, também, pelo cotejamento dos dados entre si, que a empresa está em processo de migração de uma liderança altamente formal, autoritária, transacional e, em alguns momentos, transformacional, para uma liderança mais relacional, não somente focada no indivíduo líder, mas em todos os aspectos que abrangidos por ela, como desenvolvimento de senso de compromisso, respeito mútuo e relações de confiança, anteriormente às mudanças. Quanto a isso, o Entrevistado 5 citou: 
Se um caminhão de um parceiro quebrasse, a empresa pouco se importava, nós não enxergávamos o todo, a gente não conseguia ver que ele faz parte da empresa! Não tínhamos preocupação em qualificar nossos prestadores (empresas filhas), eles tinham que tocar a empresa deles (Informação verbal, 25 de novembro de 2016).

Embora a compreensão da necessidade de uma relação mais dialógica já possa ser observada, parece necessário que a empresa mãe promova ações de comunicação mais claras e transparentes, além de fomentar maior aproximação dessas novas lideranças com a rede, tendo a finalidade de obter legitimação para os novos conceitos e para o novo estilo de liderança.

Os empreendedores mais novos e os que a nova gestão conseguiu maior aproximação relacionam vários ganhos dessa nova forma de liderar, percebendo-a como mais coletiva, mais preocupada e voltada ao todo, permitindo decisões descentralizadas, atribuindo com responsabilidade e autonomia, sem ferir princípios, valores e crenças oriundas do "DNA" da empresa mãe. No entanto, grande percurso ainda parece ser requerido até a construção do "DNA" da rede, calcado efetivamente nos propósitos que sustentam relações nessa modalidade de arquitetura organizacional, conforme o Entrevistado 3:

Uma coisa boa é tu trabalhares em uma empresa sólida, que já sabe onde quer chegar e que respeita o quanto custou chegar onde está! Outra é navegar por ondas e mares em que não se tem - leme .... A gente não consegue falar, acaba não sendo ouvido, parece que a gente não é vista. Realmente eu acho que a questão da comunicação e da circulação da informação é que tem que ser melhorada (Informação verbal, 7 de janeiro de 2017).

Esse mesmo sentimento de abandono foi reforçado por outros depoentes, que exemplificaram citando que, por vezes, não sabem ao certo quem é o seu superior ou com quem podem entrar em contato para trocar ideias ou resolver uma questão crítica. $O$ Entrevistado 6 citou:

\footnotetext{
Quando abre uma cidade nova é como um filho, você tem que cuidar do filho mais novo e acaba deixando o mais velho de lado. A distância por não estar num ponto só. Nós temos cento e poucas unidades então a distância acaba dificultando a comunicação e algumas diretrizes demoram um pouco para chegar em todas as pontas. (Informação verbal, 10 de janeiro de 2017).
}

A triangulação dos dados coletados por meio dos questionários, entrevistas e documentos analisados possibilitou constatar que a liderança relacional tende a ser o estilo de liderança mais adequado para que se efetive a liderança coletiva dentro da rede, sem haver a necessidade de legitimar uma ou outra pessoa, mas um conjunto de líderes que se 
relacionem e produzam relações sociais com toda a rede. Contudo, a empresa mãe não pode, em um momento de transição, abster-se de desenvolver novos estilos de liderança.

No intuito de sintetizar as contribuições feitas pelos participantes da pesquisa, a Figura 2 apresenta uma síntese de práticas de liderança disponíveis na revisão de literatura, associando-as com aquelas identificadas na empresa mãee nas empresas filhas da rede.

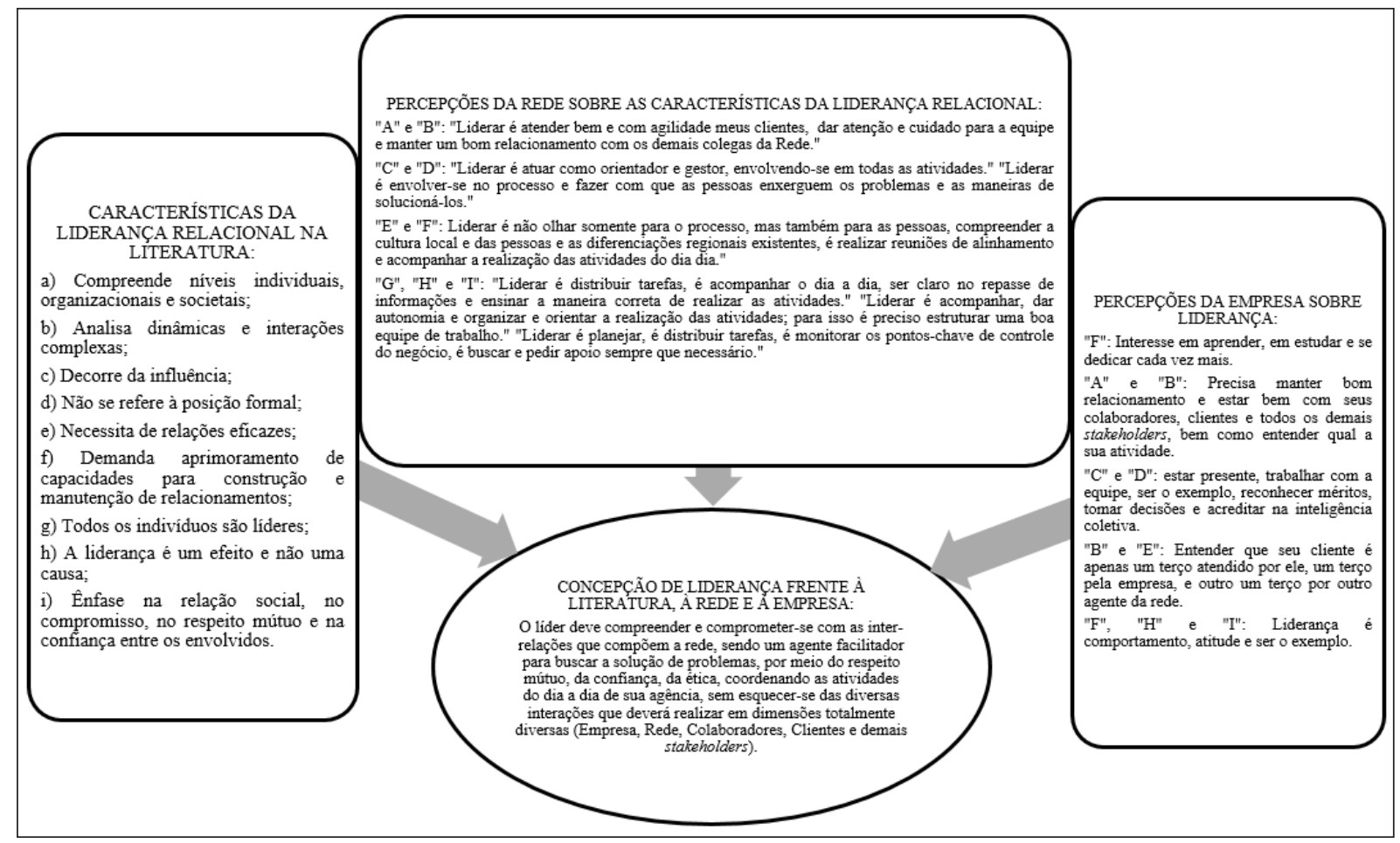

Figura 2. Concepção de liderança para a empresa, à luz das características da liderança relacional e das percepções da rede e da empresa.

Confrontando os dados, desta vez, considerando relatos das entrevistas e dados decorrentes de observação de reuniões e encontros entre a empresa mãe e empresasfilhas integrantes da rede, corroboram-se achados que apontam para estilos de lideranças fortemente centrados na noção de dominação legal. A principal evidência emergente de tal cotejamento é a ênfase colocada no legalismo do poder contratual existente entre as partes. Ressalta-se que isso se apresenta como uma marca cultural da organização e que os depoimentos dos entrevistados gestores da empresa reforçam o interesse e a vontade de permanência dessa forma de legitimação, pois ao serem questionados sobre o papel do agenciador frisaram - unanimemente-que é papel do agenciador cumprir o contrato e prestar o serviço ali disposto e que a comunicação e explicação do que ele deve fazer está prevista no contrato, reforçando o entendimento de que se trata de uma rede formal, conforme prelecionam Knorringa e Meyer-Stamer (1999).

Não foi encontrado registro de nenhum encontro ou tentativa de aproximação com a rede das principais lideranças da empresa mãe para buscar manter uma relação menos 
formal. $O$ último registro existente nos documentos analisados de encontro não formal para aproximação e melhoria do relacionamento organizacional data de 2013. Na Figura 3 buscase sumarizar os principais achados do cotejamento de dados em relatos das entrevistas e aqueles decorrentes de observação de reuniões e encontros entre a empresa mãe e empresasfilhas integrantes da rede.

Tabela 5

Resumo dos principais achados

\begin{tabular}{ll}
\hline \multicolumn{1}{c}{ Tópico } & \multicolumn{1}{c}{ Tendência observada nos dados } \\
\hline & $\begin{array}{l}\text { A empresa demanda líderes que compreendam a importância e relevância da } \\
\text { rede para a perenidade do negócio e que busquem a aproximação, realizem } \\
\text { orientaçães e repasse de conhecimento e visão para todos os prestadores de }\end{array}$ \\
$\begin{array}{l}\text { Perfil de liderança neces- } \\
\text { sário para a continuidade } \\
\text { do negócio e da rede. }\end{array}$ & $\begin{array}{l}\text { No estudo ficou evidenciado que a aproximação com a rede não está ocorrendo, } \\
\text { em razão de fatores de distância geográfica, falhas na interpretação e concep- } \\
\text { ção do que está pactuado entre as partes e até mesmo por falta de compreensão } \\
\text { do que seja o trabalho em rede. }\end{array}$ \\
\hline
\end{tabular}

O líder agenciador precisa entender, compreender e internalizar que ao mesmo

Perfil de liderança necessário para o prestador de serviços (agenciador) atender às demandas e necessidades da empresa organizada em rede.

Processos realizados pelos prestadores de serviços (empresas filhas) no desempenho de suas atividades gerenciais nos quais se evidencia a necessidade de perfil de liderança.

Como ocorre a legitimação da liderança pelos seguidores na empresa estudada. tempo que é um empreendedor, possui normas e regras a respeitar e seguir.

O líder agenciador necessário para a continuidade do negócio precisa ter a capacidade de gestar pessoas e processos, bem como administrar e conduzir seus negócios, tendo a compreensão que faz parte de uma rede de negócios e que ele somente realiza um terço do serviço que é ofertado para o seu cliente.

No estudo ficou evidenciado que a principal atividade dos líderes empresas filhas atualmente é a realização de tarefas operacionais e atendem a demandas de coleta e entrega de mercadorias e a liberação de veículos dentro dos prazos e horários acertados.

Entre os processos que devem ser e são realizados pelos líderes empresas filhas, além da gestão de sua equipe de trabalho, destacam-se a relação com a comunidade na qual estão inseridos, com clientes, sindicatos, entidades governamentais e não governamentais, com seus pares (outras casas) e com a empresa mãe, realizando interações complexas e diversas em razão da pluralidade de públicos envolvidos.

O que se identificou é que eles não são preparados ou orientados para essa complexidade e quando se deparam com ela acabam agindo pelo seu instinto, ocasionando conflitos para a empresa e para a rede.

A legitimação da alta liderança da empresa mãe é estritamente formal e burocrática, legitimada pelo contrato existente entre as partes. Não existem ações de repasse de cultura, valores e clareza de papéis e ações que devem ser realizadas pelos integrantes da rede.

A empresa possui três modelos/portes de unidades: expedidoras, equilibradas e recebedoras.

As unidades expedidoras demandam líderes com grande capacidade de delegar atribuições, sem deixar de ser exigente, primar pela qualidade, com um alto senso de urgência, que receba e siga alinhamentos claros e consistentes, com facilidade de comunicar-se com públicos diversos e com visão de investidor do negócio. Essas unidades são prioritariamente focadas em coletas de mercadorias, priorizando o foco do líder agenciador para essa tarefa especificamente.

As unidades equilibradas e as recebedoras demandam líderes objetivos, influentes e versáteis, pois precisam tanto trabalhar com situações rotineiras de coleta quanto de entrega de mercadorias e da complexidade que ambas em conjunto geram e da demanda que elas impõem à sua unidade e equipe de trabalho. A demanda de serviços e atribuições nessas unidades é superior à que é imposta sobre as unidades expedidoras. O líder dessas unidades deve ser aberto a mudanças, resiliente, capaz de tratar vários assuntos ao mesmo tempo e se relacionar com pessoas novas e diferentes diariamente. 
O conjunto dos dados, ao ser comparado com a literatura, converge no que se refere à importância da liderança para a perenidade do negócio, bem como à concepção de que - líder não pode ser analisado, mensurado e/ou identificado única e exclusivamente pela relação líder/liderado, sendo mais complexa essa interação e os níveis para os quais os líderes devem ser preparados pela organização.

Evidenciou-se, também, que a liderança efetivamente é um efeito e não uma causa; o mero fato de estar em um cargo ou posição não reforça ou empodera alguém a se intitular como líder. Tanto os entrevistados da empresa mãe quanto os das empresas filhas da rede reforçaram, em seus depoimentos, a importância de o líder conquistar a confiança, respeitar e ser exemplo para seus liderados e demais pessoas com que possui relacionamento.

Diverge da literatura a concepção da empresa mãe de que não há necessidade de ser mais clara e transparente em suas intenções, planos e pretensões com toda a rede, bem como a falta de interação mais próxima e não focada na gestão de problemas, já que uma das melhores alternativas para ocorrer a legitimação dos líderes está embasada no conhecimento dos papéis e na constituição e repasse de valores, o que não se identificou ocorrer na empresa estudada com a rede, nem ficou explicitado entre os líderes empresas filhas com seus colaboradores.

De maneira complementar, verifica-se que a liderança relacional, por ter entre suas características a ênfase na relação social, no compromisso, no respeito mútuo e na confiança entre as partes e compreender níveis individuais, organizacionais e societais, apresenta-se como um estilo de liderança capaz de suprir a necessidade e a demanda de uma empresa organizada em rede pela complexidade e pluralidade de públicos que ela possui.

Por fim, identificou-se que o perfil de liderança necessário para a continuidade do negócio e da rede em muito se assemelha ao de um agente facilitador, orientado à construção de ambiências organizacionais em que relações possam ser mediadas sem ignorar as diversas interações entre agentes-empresa mãe, empresas filhas, trabalhadores, clientes, governo, sociedade, outras redes-e interesses e atuantes em contextos com maior complexidade.

\section{CONCLUSÃO}

A liderança é um dos recursos mais demandados dentro das organizações e um dos principais fatores que podem vir a garantir a perenidade do negócio, no espaço e no tempo. Assim, este estudo primou por estudar a liderança no âmbito organizacional, focando principalmente no estudo da liderança relacional como um instrumento para aplicar a liderança coletiva em uma empresa que atua em rede. 
Segundo preleciona Vasconcellos (2005), assegurar a perpetuidade da companhia é o principal foco da liderança coletiva, porém não foram encontrados estudos específicos ou que definissem liderança coletiva, em pesquisa realizada nas bases de dados da Speel. Nesse sentido, utilizou-se a liderança relacional pela concepção e pela ampla dimensão e visão que seus preceitos proporcionam como o instrumento adequado a ser utilizado para que a liderança coletiva ocorra dentro da organização objeto do estudo.

Este estudo não pretendeu conceituar liderança, mas apresentar os principais papéis do líder e como eles são efetivados no dia a dia dentro do ambiente organizacional, bem como clarear e demonstrar a diferença de perfis e características existentes entre líderes de uma mesma organização. Embasou-se no estudo da literatura e se caracterizou como pesquisa predominantemente qualitativa, utilizando o estudo de caso como procedimento. Quanto aos fins, a pesquisa buscou descrever e interpretar os dados colhidos acerca do caso estudado, confrontando-os com a literatura.

Além da revisão bibliográfica sobre os temas envolvidos na pesquisa, foram realizadas entrevistas exploratórias, observações de reuniões e do ambiente da mpresa, análise de documentos, questionários e entrevistas com membros do corpo gerencial e diretivo e com os prestadores de serviços (empresas filhas) que compõem a rede.

A pesquisa apresenta lacunas identificadas e trianguladas entre os depoimentos dos entrevistados e a teoria, que dizem respeito à gestão da rede, à legitimidade dos líderes organizacionais, à falta de proximidade na relação da empresa com a rede, bem como que o foco principal da gestão atual está voltado para gerir um contrato, esquecendo-se das pessoas que estão envolvidas nele. Nesse sentido, apresentam-se como principais resultados:

a) a empresa mãe possui unidades diferenciadas por porte e foco do negócio, tendo unidades expedidoras, equilibradas e recebedoras, sendo que estas, em razão da diferenciação de atribuições, relações e complexidade que possuem demandam perfis de liderança diversos, porém que podem ser compreendidos e trabalhados à luz do estilo de liderança relacional pela ampla abrangência e compreensão que este proporciona do todo;

b) a empresa mãe precisa desenvolver seus gestores (supervisores, gerentes e diretores) para ampliar a visão deles do que é trabalhar em rede, da importância da rede não somente sob o aspecto financeiro, mas também social e de continuidade do negócio, com o intuito de aprimorar a legitimação deles com a rede que hoje é concebida prioritariamente pela obrigação contratual existente entre as partes;

c) a empresa mãe e as empresas filhas da rede demandam líderes com clareza do seu papel e do porte de sua unidade, capazes de buscar a resolução de problemas e conflitos, por meio do respeito mútuo, da confiança, da ética e da presença; 
de coordenar e delegar as atividades do dia a dia de sua área elou agência, sem esquecerem-se das diversas interações que deverão realizar em dimensões totalmente diversas; e que sejam hábeis para clarear e ensinar os papéis de todos os envolvidos e repassar os valores e a cultura da organização, primando pelos pontos que geram vantagem competitiva para toda a rede.

Nota-se que a rede investigada consolidou, ao longo do tempo, sua posição no mercado e criou identidade que a fez crescer e conquistar significativa fatia do mercado de transporte de cargas fracionadas da região Sul do País. Foi possível observar no estudo a visão empreendedora de seus acionistas, a inclusão constante de profissionais qualificados nos seus quadros, bem como o investimento no desenvolvimento dos profissionais que cresceram com a empresa. Essas ações possibilitaram crescimento estruturado, pela implantação de gestão profissional em uma empresa que se configura como familiar de médio porte, o que normalmente não se identifica em outras organizações similares. É possível que esses fatores tenham contribuído decisivamente para o desenvolvimento da organização.

Com a entrada em vigor da nova legislação trabal hista brasileira em novembro de 2017 , - papel da liderança, principalmente os preceitos previstos na liderança relacional, devem ser reforçados nesta e em todas as organizações que visam e demandam o desenvolvimento e o comprometimento de seu capital intelectual com a organização. Pelas novas formas contratuais que podem vir a surgir e com as novas relações de trabalho, a capacidade para engajar, comprometer e desenvolver pessoas ficará ainda maior e a necessidade de desenvolvimento da habilidade de liderar dos gestores será um diferencial competitivo cada vez mais para as organizações.

Cada empresa possui particularidades, o que impossibilita, por meio de um caso único, inferir que o que foi aqui exposto pode vir a ser aplicado em todas as organizações. Contudo, os aprendizados gerados pela análise desse caso podem trazer reflexões para outras organizações que, resguardadas suas particularidades, podem se inspirar nos resultados para promover oportunidades de melhoria no seu próprio contexto. Este estudo pode ser utilizado futuramente como base para a aplicação em redes de menor porte, com número menor de integrantes, e, principalmente, em uma rede constituída por integrantes com maiores similaridades e papéis, características e isonomias de portes e estruturas.

Por fim, uma rede é constituída pela confiança, similaridade de valores, posturas, comportamentos e uso de recursos de maneira coordenada e compartilhada. A liderança relacional é o meio pelo qual se pode estudar e aplicar essas relações, pela cooperação de atores e de processos, dada a influência e interdependência de todos esses fatores como ativos e impactantes para o todo da organização. 


\section{REFERÊNCIAS}

Bass, B. M. (1985). Leadership and performance beyon expectations. New York: Free Press.

Bergamini, C. W. (2009). Liderança: Administração do sentido (2a ed.). São Paulo: Atlas.

Casagrande, R. M., \& Lavarda, E. F. (2015, maio/ago.). Convergências teóricas entre a governança corporativa e a sustentabilidade sob a perspectiva da legitimidade. Revista de Gestão Social e Ambiental-RGSA, 9, 88-101.

Casarotto, N., Filho, Castro, J. E., Fiod, M., Neto, \& Casarotto, R. M. (1998, abr./jun.). Redes de pequenas empresas: as vantagens competitivas na cadeia de valor. Revista de Negócios Studies on emerging countries, 4.

Corrêa, G. N. (1999). Proposta de integração de parceiros na formação e gerência de empresas virtuais (Tese de doutorado). Universidade de São Paulo, São Carlos.

Day, D. V., \& Harrison, M. M. (2007). A multilevel, identity-based approach to leadership development. Human Resource Management Review, 17(4), 360-373.

Densin, N. K., \& Lincoln, Y. S. (2005). Introduction: The discipline and practice of qualitative research. In N. K. Densin \& Y. S. Lincoln, The Sage Handbook of qualitative research (4a ed., pp. 1-32). Sage: Thousand Oaks.

Fleury, A. C., \& Fleury, M. T. (2003, ago.). Estratégias competitivas e competências essenciais: perspectivas para a internacionalização da indústria no Brasil. Gestão \& Produção, 10, 129-144. doi:10.1590/S0104-530X2003000200002

Gandori, A., \& Soda, G. (1995). Inter Firm Networks: Antecedents, mechanism and Foms. Organization Studies, 16(2).

Gittell, J. H. (2011). Relational Leadership: New developments in theory and practice. Waltham, MA: Brandeis University.

Godoi, C. K., Mello, R. B., \& Silva, A. B. (2010). Pesquisa qualitativa em estudos organizacionais: Paradigmas, estratégias e métodos ( $2^{a}$ ed.). São Paulo: Saraiva.

Instituto Brasileiro de Governança Corporativa. (2014). Caderno de boas práticas de governança corporativa para empresas de capital fechado: Um guia para sociedades limitadas e sociedades por ações fechadas. São Paulo: IBGC. 
Johnson, C., Dowd, T. J., \& Ridgeway, C. L. (2006). Legitimacy as a social process. Annual Review Sociology, 53-78.

Knorringa, P., \& Meyer-Stamer, J. (1999). New dimensions in local enterprise co-operation and development: From clusters to industrial districts. In W. Suzigan (Ed.), Clusters e sistemas locais de inovação: Estudos de casos e avaliação da região de Campinas (pp. 89-115). Campinas: Unicamp.

Leon, M. E. (1998). Uma análise de redes de cooperação das pequenas e médias empresas do setor de telecomunicações (Dissertação de mestrado). Universidade de São Paulo, São Paulo.

Likert, R. (1975). Organização Humana. (M. Cotrim, Trad.). São Paulo: Atlas.

Nunes, S. C. (2010). A abordagem baseada em competências no desenvolvimento da liderança: Possíveis limitações. In R. E. Nelson \& A. de S. Sant'Anna, Liderança: Entre a tradição, a modernidade e pós-modernidade. Rio de Janeiro: Elsevier.

Olave, M. E., \& AMATO, J., Neto. (2001). Redes de cooperação produtiva: uma estratégia de competitividade e sobrevivência para pequenas e médias empresas. Gestão \& Produção, 8, 289-318. doi:10.1590/S0104-530X2001000300006

Osborn, R., Uhl-Bien, M., \& Milosevic, I. (2014). The contexto and leadership. In D. Day (Ed.), The Oxford Handbook of Leadership and Organizations (pp. 589-612). Oxford: Oxford University Press.

Ospina, S. M., \& Uhl-Bien, M. (2012). Advancing Relational Leadership Research: A Dialogue among Perspectives. Charlotte, NC: Information Age Publishers.

Ospina, S. M., Kersh, R., \& Quick, K. S. (2014). Taking a Relational Turn in Leadership Studies. Public Administration Review, 74(4), 542-544.

Ribault, M., Martinet, B., \& Lebidois, D. (1995). A gestão das tecnologias. Gestão \& Inovação. Lisboa, Portugal: Publicações Dom Quixote.

Sant'Anna, A. de S., Nelson, R. E., \& Carvalho, A., Neto. (2015). Fundamentos e dimensões da liderança relacional. DOM-Revista da Fundação Dom Cabral, 9, 16-21.

Triviños, A. N. (1987). Introdução à pesquisa em ciências sociais: A pesquisa qualitativa em educação. São Paulo: Atlas. 
Uhl-Bien, M. (2006). Relational leadership theory: Exploring the social processes of leadership and organizing. The Leadership Quaterly, 17, 654-676.

Uhl-Bien, M. (2003). Relationship development as a key ingredient for leadership development. In S. Murphy \& R. Riggio, The future of leadership development (pp. 129-147). New Jersey: Lawrence Erlbaum Associates Inc. Publishers.

Vasconcellos, P. C. (2005, abr.). O conselho de administração ideal de uma empresa. Jornal Valor Econômico.

Yin, R. K. (2010). Estudo de caso: Planejamento e métodos (4⿳a ed.). Porto Alegre: Bookman.

Como citar este artigo:

ABNT

SILVA, Éderson Tomasi da; FILIPPIM, Eliane Salete, SANT'ANNA, Anderson de Souza. Liderança relacional em rede do setor de transportes brasileiro. RACE, Revista de Administração, Contabilidade e Economia, Joaçaba: Editora Unoesc, v. 19, n. 3, p. 1-26, set./ dez. 2020. Disponível em: http://editora.unoesc.edu.br/index.php/race. Acesso em: dia/ mês/ano.

APA

Silva, É. T. da, Filippim, E. S., \& Sant'Anna, A. de S. (2020). Liderança relacional em rede do setor de transportes brasileiro. RACE, Revista de Administração, Contabilidade e Economia, 19(3), 1-26. Recuperado de http://editora.unoesc.edu.br/index.php/race 
